\title{
Beyond Marital Status: Relationship Type and Duration And the Risk of Low Birth Weight
}

\author{
By Sheryl Thorburn Bird, Anjani Chandra, Trude Bennett and S. Marie Harvey
}

\begin{abstract}
Context: Unmarried women have higher rates of low birth weight than married women. How ever, assumptions that unmarried women are uniformly at a disadvantage may be unfounded. A woman's relationship characteristics may be more relevant for infant health than her formal marital status.
\end{abstract}

Methodology: Data from the 1995 National Survey of Family Growth were used to analyze as sociations between relationship characteristics and low birth weight among U.S. women aged 15-44 with a recent singleton live birth. Unadjusted odds ratios were generated to indicate the crude effects of independent variables, including relationship type and relationship duration at the time of conception. Multiple logistic regressions were performed to assess the impact of re lationship variables on the likelihood of low birth weight, taking into account the effects of other covariates.

Results: In multivariate models of all women and non-Hispanic black women, relationship type and duration were not associated with low birth weight. However, low birth weight was almost six times as likely among Hispanic women in nonmarital, noncohabiting relationships as among those who were married. Surprisingly, among non-Hispanic white women, low birth weight was less likely among those in nonmarital, noncohabiting relationships than among those who were married. Unexpected associations also were found among low birth weight, race and ethnicity, and relationship duration: Low birth weight was more likely among non-Hispanic white women in relationships of from five to 10 years in length than among those in relationships of longer than 10 years and less likely among Hispanic women in relationships of one year or less than among those in a relationship for more than 10 years.

Conclusion: Although unmarried women in the United States have higher rates of low birth weight than married women, many unmarried women are at no greater risk of low birth weight than their married counterparts. The findings confirm the need to consider the characteristics of relationships when examining the association of mother's "union status" and birth outcomes.

Family Planning Perspectives, 2000, 32(6):281-287

$\mathrm{N}$ onmarital childbearing has increased substantially in the United States: In 1997, 32.4\% of births were to unmarried women, compared with $18.4 \%$ in $1980 .{ }^{1}$ Being unmarried is considered a risk factor for poor birth outcomes because unmarried women have overall higher rates of low birth weight and infant mortality than married women. ${ }^{2}$ However, assumptions regarding uniform disadvantage for unmarried women may be unfounded. Several studies have found that the effect of marital status on birth outcomes varies by maternal race, age and education. ${ }^{3}$ Married and unmarried women are both heterogenous groups. Characteristics of the mother's relationship with the father may be more relevant for infant health than formal marital status. In this article, we move beyond formal marital status to examine the association between key relationship characteristics and low birth weight.

Cohabitation is one relationship factor that is not captured by measures of formal marital status. The percentage of women who have cohabited by age 25 has increased: An estimated 3\% of females born in 1940-1944 had cohabited before age 25, compared with $37 \%$ of those born in $1960-1964 .{ }^{4}$ In $1995,10-11 \%$ of women aged 20-29 were currently cohabiting. ${ }^{5} \mathrm{Al}-$ though research on the birth outcomes of U.S. women generally has not considered cohabitation, studies in other countries suggest that the birth outcomes of cohabiting women may differ from those of other unmarried women. Researchers in Montreal, Canada, found that, after adjustment for confounding variables, infants of unmarried women living alone were at greater risk of low birth weight than those of married women living with their husbands, but the risk of low birth weight among infants of unmarried women living with a partner and of unmarried women living with another adult did not significantly differ from infants of married women. ${ }^{6}$ A study in Finland found that, adjusting for other factors, low birth weight, preterm delivery and peri- natal mortality were more likely among single, noncohabiting mothers than among married mothers, but the birth outcomes among cohabiting mothers were very similar to those of married women. ${ }^{7}$

However, other studies have found that neither marital status nor cohabitation was associated with birth outcomes. An examination of white women in England showed that cohabiting women differed from both married women and other unmarried women with respect to social and demographic factors, social environment, psychosocial factors, health behavior and pregnancy factors. Once controls for age and social class were introduced, marital status (categorized as being married, as cohabiting, as living with other adults or as living alone or only with children aged 15 or younger) was not associated with low birth weight. ${ }^{8}$ Similarly, an analysis of data on U.S. women from the $1988 \mathrm{Na-}$ tional Maternal and Infant Health Survey found that family structure (measured by marital status and living arrangements) was related neither to birth weight nor to infant mortality. ${ }^{9}$

Like cohabitation, relationship duration is one of the main demographic characteristics of relationships and may be associated with commitment, intimacy ${ }^{10}$ and-because longer relationships may have greater stability and be more supportive of health-promoting behaviorsbirth outcomes. To our knowledge, no one has examined the association between relationship duration and low birth weight.

Marital status is thought to be related to socioeconomic status, pregnancy intendedness and social support. ${ }^{11}$ Researchers have suggested that these and other factors, such as maternal smoking, may explain the inconsistent association between marital status and infant health. ${ }^{12}$ Because

Sheryl Thorburn Bird is a research associate with the Center for the Study of Women in Society, University of Oregon, Eugene; Anjani Chandra is a demographer with the Reproductive Statistics Branch, Division of Vital Statistics, National Center for Health Statistics, Hyattsville, MD; Trude Bennett is associate professor, Department of Maternal and Child Health, School of Public Health, University of North Carolina at Chapel Hill; and S. Marie Harvey is associate professor of public health and research director, Center for the Study of Women in Society, University of Oregon, Eugene. 
studies that have sought to improve understanding of the relationship between marital status and birth outcomes among U.S. women generally have relied on vital statistics data, the variables that could be included in such analyses were limited to those collected on birth certificates (which record only the formal marital status of the mother) and on death certificates.

Research that examines cohabitation, other relationship characteristics and other potential correlates of low birth weight may improve understanding of whether or how marital status is associated with low birth weight. Data from the $1995 \mathrm{Na}-$ tional Survey of Family Growth (NSFG) include birth weight and informal marital status, as well as many other variables. Thus, we analyzed data from the 1995 NSFG to examine the association between the characteristics of a woman's relationship with the father of her child and low birth weight while adjusting for a variety of factors known or thought to be associated with maternal and infant health.

\section{Data and Methodology}

\section{The Survey}

The NSFG is a periodic survey of women of reproductive age conducted by the National Center for Health Statistics. All five rounds of the NSFG to date have been based on multistage probability sampling of the civilian noninstitutionalized population of females aged 15-44 in the United States, yielding estimates that are representative of the national population of women in this age range. The main purpose of the NSFG is to collect data on factors affecting pregnancy and women's health in the United States.

In our research, we used data from the 1995 NSFG, for which the sample consisted of 10,847 women with whom inperson, in-home interviews were conducted. Black and Hispanic women were oversampled. The response rate for the 1995 NSFG was $79 \%$.

Women in the 1995 NSFG were asked about all pregnancies they had ever had and, for each pregnancy, about its characteristics, including date of outcome and birth weight (in the case of a live birth). (The NSFG estimates of low birth weight rates based on mothers' reports are comparable to low birth weight rates based on birth certificate data. ${ }^{13}$ ) In addition, for recent pregnancies (those between January 1991 and the interview date in 1995), women were asked about pregnancy complications, prenatal care and smoking during pregnancy.

For reasons of sensitivity and confidentiality, women in the NSFG were not asked directly about the father of each pregnancy, with the exception of his age at the time she became pregnant and the extent to which he wanted the pregnancy at that time. In 1995, women also were asked their sexual partner history, which can be used in conjunction with their pregnancy history to determine which husband or partner was most likely involved in each of their pregnancies.

The greatest detail in these histories is available for the period beginning with January 1991, roughly the five years before the interview. Therefore, we limited our sample to the most recent singleton live births reported in January 1991 or later $(n=2,711)$. We used the most recent birth to avoid multiple observations per woman. We restricted our analysis to singleton births because multiple births are at higher risk of low birth weight, which is our outcome of interest, and the NSFG does not include sufficient cases of multiple births to examine this factor reliably.

We used dates of marriage, cohabitation and sexual relationships in conjunction with birth dates and estimated dates of conception to identify all possible fathers for each birth. We defined one variable for who the father was and a separate variable for the certainty with which the father had been identified. We divided the latter variable into three categories: The father was considered "identified definitively" if the woman reported only one husband or partner with whom she had had a sexual relationship within dates compatible with the estimated date of conception; the father was classified as "identified probably" if the woman reported two or more "possible fathers"-that is, men with whom she had had a relationship within dates compatible with the estimated date of conception; and the father was considered "not identified" if the woman did not report a husband or partner with whom she had had a sexual relationship within dates compatible with the estimated date of conception.

In cases where there were two or more possible fathers, we gave preference first to husbands, then to cohabiting partners and finally to other sexual partners; however, the "certainty" variable was defined as "father identified probably." We excluded 143 cases for which no father could be identified. Of the remaining 2,578 births in the final sample, the father was identified definitively in $83 \%$ and probably in $17 \%$.

\section{Measures}

We defined low birth weight, our dependent variable, as infant birth weight less than 2,500 g, or 5 lbs. 9 oz. Our key rela- tionship variables of interest were relationship type and duration. For relationship type at conception, we used the variable defining who the father was to create a variable with three categories describing the relationship between the woman and the father of the child at the time of conception: married, cohabiting or other type of relationship. For relationship duration at conception, we used the variable defining who the father was, the date of first sex with the father and the date of conception to create a variable indicating the number of months between the woman's first sex with the father and date of conception. Based on the distribution of this variable, we then grouped the number of months into four categories: 12 months or less, 13-60 months, 61-120 months and 121 months or more.

We also examined several potential correlates of relationship variables and low birth weight, such as a woman's age at the time of conception, her race and ethnicity and her education at interview. We included race and ethnicity because fertility, marriage patterns and low birth weight rates are known to vary by race and ethnicity. ${ }^{14}$ We did not use education at conception because the event-history data for education in the 1995 NSFG could not be used to generate a consistently defined measure for women of all ages in the sample.

We also considered the woman's report of the father's age at the time of conception. We did not include the father's race and ethnicity in the analyses presented here because it was so highly correlated with the woman's race and ethnicity. We did not analyze the father's level of education because these data were not collected consistently in the 1995 NSFG.

Finally, we analyzed women's pregnancy and delivery characteristics, such as intendedness at the time of conception, whether they smoked during the pregnancy, the timing of their first prenatal care visit, the location of most prenatal care visits, the type of payment for their delivery and their child's birth order. Intendedness has three categories: intended (the pregnancy was wanted at the time of conception or sooner), mistimed (the pregnancy was wanted but occurred sooner than desired) and unwanted (the pregnancy was not wanted at the time of conception or later). The variable for location of most prenatal care visits had three categories: private physician or health maintenance organization (HMO), clinic and "other" (including midwives and charitable hospitals). When appropriate, reports of "other" sites were recorded by the NSFG 
staff as private physician or HMO or clinic. We could not examine the number of prenatal care visits because those data were not collected in the 1995 NSFG.

\section{Analyses}

The descriptive results are presented as weighted percentages, using a poststratified weight adjusted for nonresponse and sample design. Standard errors for all bivariate and multivariate analyses have been computed using SUDAAN statistical software in conjunction with SAS, to account for the complex survey design of the NSFG. We determined whether differences in percentages were statistically significant at the $5 \%$ alpha level by assessing overlap between the percentages' $95 \%$ confidence intervals. We generated unadjusted odds ratios to indicate the crude effects of each independent variable among all women.

To address the possibility of interactions among race and ethnicity, low birth weight and other variables, we also examined unadjusted odds ratios within the racial and ethnic groups considered. For example, if there were an interaction among race and ethnicity, relationship characteristics and low birth weight, we would expect to see different associations between relationship characteristics and low birth weight across the different racial and ethnic groups.

To assess the impact of the relationship variables on the likelihood of low birth weight, excluding other covariates, we performed multiple logistic regressions. Using SUDAAN's RLOGIST procedure, we estimated the odds of low birth weight associated with relationship characteristics for a woman's most recent singleton live birth after adjusting for selected characteristics. We did not include father's age at conception or timing of first prenatal care in the final logistic regressions because their unadjusted odds ratios were not significant at the $10 \%$ alpha level.

\section{Results}

\section{Characteristics by Relationship Type}

More than two-thirds (69\%) of U.S. women with a recent singleton birth were married to the father of the baby at the time of conception, $12 \%$ were cohabiting and $19 \%$ had some other type of relationship with the father.* Of those women who were not married to the father at conception (approximately 4.1 million women), almost $40 \%$ were cohabiting with him.

There was not a statistically significant difference by relationship type at conception in the percentages of women

Table 1. Percentage distribution (and standard errors) of U.S. women aged 15-44 with a recent singleton birth, by selected characteristics, according to relationship type at conception, 1995 National Survey of Family Growth

\begin{tabular}{|c|c|c|c|c|}
\hline \multirow[t]{2}{*}{ Characteristic } & \multirow{2}{*}{$\begin{array}{l}\text { All } \\
(\mathrm{N}=2,578)\end{array}$} & \multicolumn{3}{|c|}{ Relationship type } \\
\hline & & $\begin{array}{l}\text { Married } \\
(\mathrm{N}=1,675)\end{array}$ & $\begin{array}{l}\text { Cohabiting } \\
(\mathrm{N}=341)\end{array}$ & $\begin{array}{l}\text { Other } \\
(\mathrm{N}=562)\end{array}$ \\
\hline \multicolumn{5}{|c|}{ Relationship duration at conception (in mos.)† } \\
\hline$\leq 12$ & 17.6 & $4.3(0.6)$ & $32.2(3.3)$ & $56.1(2.6)$ \\
\hline $13-60$ & 36.9 & $35.1(1.3)$ & $49.8(3.6)$ & $35.7(2.4)$ \\
\hline $61-120$ & 30.5 & $40.1(1.2)$ & $14.9(2.3)$ & $5.7(1.1)$ \\
\hline$\geq 121$ & 15.0 & $20.6(1.1)$ & $3.2(1.1)$ & $2.5(0.7)$ \\
\hline \multicolumn{5}{|l|}{ Age at conception } \\
\hline$<20$ & 13.7 & $4.4(0.6)$ & $21.1(2.8)$ & $43.0(2.3)$ \\
\hline $20-34$ & 77.2 & $84.5(1.0)$ & $73.1(3.0)$ & $53.2(2.4)$ \\
\hline $35-44$ & 9.1 & $11.2(0.9)$ & $5.8(1.5)$ & $3.9(0.8)$ \\
\hline \multicolumn{5}{|l|}{ Race/ethnicity } \\
\hline Hispanic & 15.5 & $14.5(1.2)$ & $21.0(2.7)$ & $15.4(1.7)$ \\
\hline Non-Hispanic black & 12.9 & $5.2(0.5)$ & $17.8(2.2)$ & $37.8(2.5)$ \\
\hline Non-Hispanic white/other & 71.7 & $80.4(1.3)$ & $61.2(3.2)$ & $46.8(2.7)$ \\
\hline \multicolumn{5}{|l|}{ Education at interview } \\
\hline$<$ high school graduate & 17.1 & $10.5(0.9)$ & $35.1(3.5)$ & $29.8(1.9)$ \\
\hline$\geq$ high school graduate & 82.9 & $89.5(0.9)$ & $65.0(3.5)$ & $70.2(1.9)$ \\
\hline \multicolumn{5}{|c|}{ Age of father of child at conception† } \\
\hline$<20$ & 6.3 & $0.9(0.3)$ & $12.1(2.4)$ & $22.6(2.0)$ \\
\hline $20-34$ & 73.7 & $75.0(1.2)$ & $72.8(3.1)$ & $69.2(2.2)$ \\
\hline$\geq 35$ & 20.1 & $24.1(1.2)$ & $15.1(2.2)$ & $8.2(1.3)$ \\
\hline \multicolumn{5}{|l|}{ Pregnancy intendedness $\ddagger$} \\
\hline Intended & 69.3 & $79.9(1.1)$ & $59.0(3.1)$ & $37.5(2.1)$ \\
\hline Mistimed & 21.4 & $12.8(0.9)$ & $27.7(3.3)$ & $48.9(2.2)$ \\
\hline Unwanted & 9.0 & $7.2(0.6)$ & $13.0(2.1)$ & $13.1(1.6)$ \\
\hline \multicolumn{5}{|c|}{ Smoking during pregnancy† } \\
\hline Yes & 16.7 & $13.8(1.0)$ & $30.6(3.4)$ & $18.7(2.0)$ \\
\hline No & 83.3 & $86.2(1.0)$ & $69.5(3.4)$ & $81.3(2.0)$ \\
\hline \multicolumn{5}{|c|}{ Timing of first prenatal care visit $†$} \\
\hline First four months & 94.4 & $96.0(0.6)$ & $93.5(1.3)$ & $89.4(1.5)$ \\
\hline Later/never & 5.6 & $4.0(0.6)$ & $6.5(1.3)$ & $10.6(1.5)$ \\
\hline \multicolumn{5}{|c|}{ Site of most prenatal care visits $\dagger$} \\
\hline Private MD/HMO & 75.5 & $82.7(1.3)$ & $64.1(3.0)$ & $56.2(2.7)$ \\
\hline Clinic & 21.2 & $14.5(1.2)$ & $31.0(2.6)$ & $39.7(2.6)$ \\
\hline Other & 3.3 & $2.8(0.4)$ & $4.9(1.5)$ & $4.1(0.9)$ \\
\hline \multicolumn{5}{|l|}{ Payment for delivery } \\
\hline Private insurance & 59.5 & $71.6(1.5)$ & $38.7(3.5)$ & $29.1(2.4)$ \\
\hline Medicaid/govt. assistance & 33.1 & $19.6(1.3)$ & $57.6(3.4)$ & $66.5(2.5)$ \\
\hline All other & 7.4 & $8.9(0.9)$ & $3.8(1.1)$ & $4.5(1.0)$ \\
\hline \multicolumn{5}{|l|}{ Infant birth order } \\
\hline 1 & 38.4 & $31.3(1.3)$ & $39.1(3.4)$ & $63.4(2.4)$ \\
\hline $2-3$ & 52.3 & $58.7(1.3)$ & $49.6(3.3)$ & $30.5(2.2)$ \\
\hline$\geq 4$ & 9.4 & $9.9(0.8)$ & $11.4(1.6)$ & $6.1(1.1)$ \\
\hline \multicolumn{5}{|l|}{ Low infant birth weight } \\
\hline Yes & 4.6 & $3.9(0.5)$ & $6.2(1.3)$ & $6.2(1.2)$ \\
\hline No & 95.4 & $96.1(0.5)$ & $93.8(1.3)$ & $93.8(1.2)$ \\
\hline Total & 100.0 & 100.0 & 100.0 & 100.0 \\
\hline No. (in millions) & 13.3 & 9.2 & 1.6 & 2.5 \\
\hline
\end{tabular}

$\dagger$ Data for this variable were missing for some cases; missing data were not included in calculations of percentages. $¥$ Cases for which pregnancy intendedness was undetermined are included in the total. Note: All Ns are unweighted; all percentages are weighted.

whose infants weighed less than 2,500 g (Table 1). However, there were statistically significant differences by relationship type in the characteristics of women and their relationships. For example, cohabiting women tended to be in relationships that were shorter in duration at the time of conception than those of married women and longer in duration than those of unmarried, noncohabiting women. Cohabiting women were younger than married women and older than women in other types of nonmarital relationships. In addition, there was a statistically significant difference in the percentage distributions of women in each type of rela-

*Percentages are weighted. 
Table 2. Percentage distribution (and standard errors) of U.S. women aged 15-44 with a recent singleton birth, by selected characteristics, according to relationship duration at conception

\begin{tabular}{|c|c|c|c|c|c|}
\hline \multirow[t]{2}{*}{ Characteristic } & \multirow{2}{*}{$\begin{array}{l}\text { All } \\
(\mathrm{N}=2,578)\end{array}$} & \multicolumn{4}{|c|}{ Relationship duration (in months) } \\
\hline & & $\begin{array}{l}\leq 12 \\
(\mathrm{~N}=436)\end{array}$ & $\begin{array}{l}13-60 \\
(\mathrm{~N}=908)\end{array}$ & $\begin{array}{l}61-120 \\
(\mathrm{~N}=730)\end{array}$ & $\begin{array}{l}\geq 121 \\
(N=355)\end{array}$ \\
\hline \multicolumn{6}{|c|}{ Relationship type at conception } \\
\hline Married & 68.9 & $16.7(2.2)$ & $65.4(1.8)$ & $90.6(1.1)$ & $94.4(1.1)$ \\
\hline Cohabiting & 12.1 & $21.4(2.4)$ & $15.8(1.3)$ & $5.7(0.9)$ & $2.5(0.8)$ \\
\hline Other & 19.0 & $61.9(3.0)$ & $18.8(1.6)$ & $3.7(0.7)$ & $3.2(0.8)$ \\
\hline \multicolumn{6}{|l|}{ Age at conception } \\
\hline$<20$ & 13.7 & $42.6(2.8)$ & $15.5(1.3)$ & $0.7(0.3)$ & $0.0(0.0)$ \\
\hline $20-34$ & 77.2 & $54.7(2.8)$ & $78.1(1.5)$ & $90.8(1.4)$ & $74.2(2.5)$ \\
\hline $35-44$ & 9.1 & $2.7(0.8)$ & $6.4(0.8)$ & $8.5(1.3)$ & $25.8(2.5)$ \\
\hline \multicolumn{6}{|l|}{ Race/ethnicity } \\
\hline Hispanic & 15.5 & $20.2(2.2)$ & $16.6(1.6)$ & $13.6(1.3)$ & $13.5(2.4)$ \\
\hline Non-Hispanic black & 12.9 & $22.4(2.1)$ & $14.9(1.4)$ & $8.0(0.9)$ & $6.2(1.0)$ \\
\hline Non-Hispanic white/other & 71.7 & $57.5(2.7)$ & $68.5(1.9)$ & $78.4(1.5)$ & $80.3(2.4)$ \\
\hline \multicolumn{6}{|l|}{ Education at interview } \\
\hline <high school graduate & 17.1 & $33.8(2.6)$ & $16.7(1.3)$ & $9.5(1.2)$ & $13.6(2.3)$ \\
\hline$\geq$ high school graduate & 82.9 & $66.2(2.6)$ & $83.3(1.3)$ & $90.5(1.2)$ & $86.4(2.3)$ \\
\hline \multirow{2}{*}{\multicolumn{6}{|c|}{ Age of father of child at conceptiont }} \\
\hline & & & & & $0.0(0.0)$ \\
\hline 20-34 & 73.7 & $70.2(2.5)$ & $80.1(1.5)$ & $79.6(1.7)$ & $49.6(3.0)$ \\
\hline$\geq 35$ & 20.1 & $7.8(1.4)$ & $13.7(1.3)$ & $20.4(1.7)$ & $50.4(3.0)$ \\
\hline \multicolumn{6}{|l|}{ Pregnancy intendedness $\neq$} \\
\hline Intended & 69.3 & $44.2(2.7)$ & $70.0(1.8)$ & $80.3(1.4)$ & $77.1(2.3)$ \\
\hline Mistimed & 21.4 & $44.6(2.5)$ & $22.4(1.6)$ & $12.8(1.3)$ & $7.6(1.4)$ \\
\hline Unwanted & 9.0 & $11.1(1.6)$ & $7.2(0.9)$ & $6.5(0.9)$ & $15.3(2.1)$ \\
\hline \multicolumn{6}{|c|}{ Smoking during pregnancy $\dagger$} \\
\hline Yes & 16.7 & $18.7(2.4)$ & $16.4(1.4)$ & $13.3(1.4)$ & $16.9(2.0)$ \\
\hline No & 83.3 & $81.3(2.4)$ & $83.6(1.4)$ & $86.7(1.4)$ & $83.1(2.0)$ \\
\hline \multicolumn{6}{|c|}{ Timing of first prenatal care visit $†$} \\
\hline First four months & 94.4 & $93.5(1.2)$ & $94.4(0.8)$ & $95.0(1.0)$ & $95.3(1.4)$ \\
\hline Later/never & 5.6 & $6.5(1.2)$ & $5.6(0.8)$ & $5.0(1.0)$ & $4.7(1.4)$ \\
\hline \multicolumn{6}{|c|}{ Site of most prenatal care visits $\dagger$} \\
\hline Private $\mathrm{MD} / \mathrm{HMO}$ & 75.5 & $62.4(3.1)$ & $74.5(1.6)$ & $80.4(1.8)$ & $83.6(2.2)$ \\
\hline Clinic & 21.2 & $33.2(2.9)$ & $21.8(1.5)$ & $16.8(1.7)$ & $14.0(2.1)$ \\
\hline Other & 3.3 & $4.4(1.1)$ & $3.7(0.6)$ & $2.8(0.7)$ & $2.4(1.0)$ \\
\hline \multicolumn{6}{|l|}{ Payment for delivery } \\
\hline Private insurance & 59.5 & $34.6(3.0)$ & $55.4(2.1)$ & $73.6(1.7)$ & $75.1(2.5)$ \\
\hline Medicaid/govt. assistance & 33.1 & $58.5(3.2)$ & $37.1(2.0)$ & $19.0(1.6)$ & $16.8(2.3)$ \\
\hline All other & 7.4 & $6.9(1.7)$ & $7.6(1.2)$ & $7.4(1.1)$ & $8.1(1.4)$ \\
\hline \multicolumn{6}{|l|}{ Infant birth order } \\
\hline 1 & 38.4 & $70.5(2.5)$ & $44.4(2.0)$ & $25.3(1.8)$ & $12.6(2.0)$ \\
\hline $2-3$ & 52.3 & $26.0(2.4)$ & $49.8(2.0)$ & $65.3(1.8)$ & $63.2(2.8)$ \\
\hline$\geq 4$ & 9.4 & $3.5(0.8)$ & $5.8(0.9)$ & $9.4(1.0)$ & $24.1(2.5)$ \\
\hline \multicolumn{6}{|l|}{ Low infant birth weight } \\
\hline Yes & 4.6 & $5.8(1.3)$ & $4.6(0.6)$ & $4.8(1.0)$ & $3.1(1.0)$ \\
\hline No & 95.4 & $94.2(1.3)$ & $95.4(0.6)$ & $95.2(1.0)$ & $96.9(1.0)$ \\
\hline Total & 100.0 & 100.0 & 100.0 & 100.0 & 100.0 \\
\hline No. (in millions) & 13.3 & 2.2 & 4.6 & 3.8 & 1.9 \\
\hline
\end{tabular}

†Data for this variable were missing for some cases; missing data were not included in calculations of percentages. $¥$ Cases for which pregnancy intendedness was undetermined are included in the total. Note: All Ns are unweighted; all percentages are weighted.

tionship by race and ethnicity, with the exception that there was not a statistically significant difference in the percentages of women who were Hispanic in each type of relationship.

Intended pregnancies comprised 59\% of births to women who were cohabiting with the father at conception, compared with $80 \%$ of births to women who were married and $38 \%$ of births to women in some other type of relationship. The rate a statistically significant difference between the percentage of married women $(96 \%)$ and the percentage of women in nonmarital, noncohabiting relationships $(89 \%)$ who initiated prenatal care within the first four months of their pregnancy.

Women who were cohabiting with the father at the time of conception resembled other unmarried women with respect to the location of most prenatal care visits: Almost one-third of cohabiting women and $40 \%$ of women in other types of nonmarital relationships at conception obtained most of their prenatal care from a clinic, compared with $15 \%$ of women who were married at conception. Married women mentioned Medicaid or government assistance as a source of payment for delivery approximately one-third as often $(20 \%)$ as women who were cohabiting $(58 \%)$ or were in other types of nonmarital relationships $(67 \%)$ at the time of conception. Finally, cohabiting women were similar to those who were married at conception in that for the majority the resulting birth was not their first.

Characteristics by Relationship Duration There was not a statistically significant difference in low birth weight among women in relationships of different duration (Table 2). In general, the largest percentage-point differences according to relationship duration were between women who had a relationship with the father of the baby for 12 months or less at the time of conception and those in relationships of longer duration. Women in relationships in duration of one year or less at conception were more likely than women in longer relationships to have had a nonmarital, noncohabiting relationship with the father, to be younger than 20 or to be non-Hispanic black. Forty-four percent of women in relationships in duration of 12 months or less at conception reported that they intended to become pregnant, compared with $70-80 \%$ of those in relationships of more than a year in duration.

The percentage of women who obtained most of their prenatal care from a clinic was significantly higher among those who had been with their partner for a year or less at conception (33\%) than among those in longer term relationships (14-22\%). Private insurance paid for delivery for approximately one-third of the women in relationships of 12 months or less in duration at conception, compared with $55-75 \%$ of women in longer-term relationships. Maternal smoking and timing of first prenatal care visit did not differ significantly according to relationship duration at conception. 
Relationships and Low Birth Weight

There was a statistically significant difference according to race and ethnicity in the percentage distributions of women by relationship type and relationship duration (Table 3). For example, higher percentages of non-Hispanic white women than non-Hispanic black or Hispanic women were married and in relationships in duration of from five to 10 years at the time of conception (Table 3 ).

We calculated the unadjusted odds ratios for low birth weight associated with selected characteristics for a woman's most recent singleton live birth for all women and separately for non-Hispanic white women, nonHispanic black women and Hispanic women. Here, we present the results pertaining to the relationship variables. Among all women, low birth weight was more likely among infants both of women who were cohabiting and of women who had some other type of nonmarital relationship with the baby's father at the time of conception than among married women (odds ratios, 1.6). Within racial and ethnic groups, the unadjusted odds ratios for low birth weight according to relationship type were not statistically significant. These results differ from those presented in Table 1, which may be because the small sample size for women whose infants had low birth weight was not adequate to detect a significant difference in percentages at the $5 \%$ alpha level.

The unadjusted odds ratios for low birth weight among all women according to relationship duration were not statistically significant. How ever, among nonHispanic white women, low birth weight was more than four times as likely among those with relationships of 12 months or less at conception as among those in relationships of longer than 10 years. There was no difference in the unadjusted odds ratios for low birth weight among nonHispanic black or Hispanic women according to relationship duration.

As shown in Table 4 (page 286), after adjusting for selected characteristics, we found that the effects of relationship type and relationship duration were statistically significant for non-Hispanic white women and Hispanic women. Among non-Hispanic white women, compared with those who were married at the time of conception, low birth weight was less likely among those who were in nonmarital, noncohabiting relationships (odds ratio, 0.1) at the time of conception. In addition, low birth weight was three times as likely among non-Hispanic white women in relationships of from five to 10 years duration as among those in relationships of longer than 10 years.

Furthermore, compared with Hispanic women who were married to the child's father at the time of conception, low birth weight was almost six times as likely among Hispanic women who were in nonmarital, noncohabiting relationships. In contrast, low birth weight was less likely among Hispanic women in relationships of one year or less at the time of conception than among those in relationships of more than 10 years.

\section{Discussion}

Not all nonmarital relationships are associated with an elevated risk of low birth weight. In unadjusted and adjusted analyses of racial and ethnic groups, low birth weight was no more likely among women who were cohabiting at the time of conception than it was among women who were married at the time of conception. In addition, among non-Hispanic black women, low birth weight was no more likely among women in nonmarital, noncohabiting relationships at conception than among married women. Furthermore, although the unadjusted odds ratios for relationship type were statistically significant when data for all women were analyzed, the adjusted odds ratios were not.

Our findings provide further evidence that being unmarried, per se, is not detrimental to infant health. Rather, our findings and related research ${ }^{15}$ suggest that other factors account for the higher rates of low birth weight among unmarried women compared with married women. An advantage of using the 1995 NSFG instead of vital statistics data is that we were able to examine the association between relationship characteristics and low birth weight, having controlled for several other variables. From our findings, however, we do not know the extent to which individual variables account for differences in the unadjusted and adjusted results. Future research could examine the influence of specific factors, such as maternal smoking and location of most prenatal care visits.

Hispanic women in noncohabiting relationships (19\% of Hispanic women) were at increased risk of low birth weight. A possible explanation is that Hispanic women in nonmarital, noncohabiting relationships who become pregnant may receive less so- cial or economic support from family and friends or experience more stress associated with not living with the baby's father than do non-Hispanic women in similar types of relationships. Research that examines the broader social context in which Hispanic women conceive and nurture pregnancies may identify differences between women in cohabiting and other nonmarital relationships that we did not explore here.

Surprisingly, compared with the infants of non-Hispanic white women who were married at the time of conception, infants of non-Hispanic white women who were in nonmarital, noncohabiting relationships were less likely to have low birth weight. It may be that this group of unmarried women includes a greater proportion of professional women who have higher incomes and better resources than other unmarried women. These women also may be more likely to have other supportive relationships. Research that examines these factors may help explain our findings.

Our findings with respect to relationship duration for both non-Hispanic white and Hispanic women also are puzzling. These results may reflect the interaction among age, birth order and relationship variables, but because sample sizes were small, we did not examine interactions among variables. The relationship duration results for Hispanic women also may be affected by the small number of cases, especially when all variables are cross-classified.

In general, a limitation of the NSFG is its relatively small sample size for examining events such as low birth weight. Although p-values less than 0.05 allow us to conclude that there is a relationship between variables, the wide confidence bands for some odds ratios indicate that precision could be im- 
Table 4. Adjusted odds ratios (and 95\% confidence intervals) from logistic regression analysis of low birth weight in a woman's most recent singleton live birth, by characteristic, according to race and ethnicity

\begin{tabular}{|c|c|c|c|c|}
\hline Characteristic & $\begin{array}{l}\text { All } \\
(\mathrm{N}=2,356)\end{array}$ & $\begin{array}{l}\text { Non-Hispanic } \\
\text { white } \\
(\mathrm{N}=1,297)\end{array}$ & $\begin{array}{l}\text { Non-Hispanic } \\
\text { black } \\
(\mathrm{N}=505)\end{array}$ & $\begin{array}{l}\text { Hispanic } \\
(\mathrm{N}=475)\end{array}$ \\
\hline \multicolumn{5}{|l|}{ Relationship type at conception } \\
\hline Married (ref) & 1.0 & 1.0 & 1.0 & 1.0 \\
\hline Cohabiting & $0.9(0.5-1.7)$ & $0.8(0.3-2.1)$ & $1.4(0.5-3.8)$ & $1.0(0.2-4.7)$ \\
\hline Other & $0.6(0.3-1.2)$ & $0.1^{*}(0.0-0.6)$ & $1.5(0.5-4.4)$ & $5.7^{* \star}(2.1-15.1)$ \\
\hline \multicolumn{5}{|c|}{ Relationship duration at conception (in mos.) } \\
\hline$\leq 12$ & $1.6(0.6-4.7)$ & $4.8(0.9-26.4)$ & $0.9(0.2-5.0)$ & $0.1^{*}(0.0-0.7)$ \\
\hline $13-60$ & $1.4(0.6-3.2)$ & $2.4(0.7-8.4)$ & $1.1(0.3-4.5)$ & $0.2(0.0-1.9)$ \\
\hline $61-120$ & $1.9(0.9-3.8)$ & $3.1^{*}(1.0-9.7)$ & $1.4(0.3-5.6)$ & $0.4(0.1-2.6)$ \\
\hline$\geq 121$ (ref) & 1.0 & 1.0 & 1.0 & 1.0 \\
\hline \multicolumn{5}{|l|}{ Age at conception } \\
\hline$<20$ & $0.7(0.4-1.3)$ & $0.7(0.2-2.4)$ & $0.8(0.3-2.3)$ & $0.6(0.2-2.0)$ \\
\hline 20-34 (ref) & 1.0 & 1.0 & 1.0 & 1.0 \\
\hline $35-44$ & $1.9(0.9-4.0)$ & $1.1(0.3-4.1)$ & $6.9^{\star *}(2.1-22.4)$ & $0.7(0.1-7.1)$ \\
\hline \multicolumn{5}{|l|}{ Race/ethnicity } \\
\hline Hispanic & $1.3(0.7-2.5)$ & na & na & na \\
\hline Non-Hispanic black & $3.3^{\star * *}(2.2-5.0)$ & na & na & na \\
\hline Non-Hispanic white/other (ref) & 1.0 & na & na & na \\
\hline \multicolumn{5}{|l|}{ Education at interview } \\
\hline <high school graduate (ref) & 1.0 & 1.0 & 1.0 & 1.0 \\
\hline$\geq$ high school graduate & $1.1(0.5-2.1)$ & $1.0(0.4-2.8)$ & $1.4(0.6-3.7)$ & $1.1(0.3-4.1)$ \\
\hline \multicolumn{5}{|l|}{ Pregnancy intendedness } \\
\hline Intended (ref) & 1.0 & 1.0 & 1.0 & 1.0 \\
\hline Mistimed & $1.7^{*}(1.0-2.8)$ & $1.6(0.8-3.5)$ & $2.1(0.9-5.1)$ & $1.3(0.5-3.8)$ \\
\hline Unwanted & $0.7(0.3-1.5)$ & $1.2(0.3-4.0)$ & $0.6(0.2-1.8)$ & $0.0^{* * *}(0.0-0.0)$ \\
\hline \multicolumn{5}{|l|}{ Smoking during pregnancy } \\
\hline Yes & $2.0^{* *}(1.3-3.3)$ & $2.9^{\star *}(1.6-5.3)$ & $0.6(0.2-2.0)$ & $\dagger$ \\
\hline No (ref) & 1.0 & 1.0 & 1.0 & $\dagger$ \\
\hline \multicolumn{5}{|l|}{ Site of most prenatal care visits } \\
\hline Private MD/HMO (ref) & 1.0 & 1.0 & 1.0 & 1.0 \\
\hline Clinic & $1.3(0.8-2.2)$ & $1.2(0.5-3.2)$ & $0.9(0.5-1.8)$ & $3.2(0.8-12.0)$ \\
\hline Other & $2.8^{*}(1.3-5.9)$ & $4.3^{*}(1.3-14.4)$ & $1.9(0.5-6.5)$ & $2.5(0.3-22.6)$ \\
\hline \multicolumn{5}{|l|}{ Payment for delivery } \\
\hline Private insurance (ref) & 1.0 & 1.0 & 1.0 & 1.0 \\
\hline Medicaid/govt. assistance & $1.6(0.9-2.8)$ & $2.1(0.9-5.0)$ & $1.6(0.8-3.1)$ & $1.0(0.3-4.0)$ \\
\hline All other & $0.9(0.4-2.4)$ & $1.3(0.4-4.2)$ & $0.4(0.0-4.3)$ & $0.5(0.0-7.0)$ \\
\hline \multicolumn{5}{|l|}{ Infant's birth order } \\
\hline 1 & $1.8^{*}(1.1-2.9)$ & $2.3^{*}(1.1-4.6)$ & $1.1(0.4-2.6)$ & $1.3(0.4-4.6)$ \\
\hline $2-3$ (ref) & 1.0 & 1.0 & 1.0 & 1.0 \\
\hline$\geq 4$ & $2.3^{*}(1.2-4.4)$ & $3.4^{*}(1.3-8.7)$ & $2.5(0.8-7.6)$ & $0.4(0.1-2.6)$ \\
\hline
\end{tabular}

${ }^{*}$ Statistically significant at $p<.05$. ${ }^{* *}$ Statistically significant at $p<.005 .{ }^{* * *}$ Statistically significant at $p<.0005$. $†$ Although included in the model, maternal smoking was too rare among Hispanic women to produce statistically reliable estimates for this group. Notes: ref=reference group. na=not applicable. Age of father at conception and timing of first prenatal care visit were not included in the final logistic regression models because their unadjusted odds ratios were not statistically significant at $p<10$. Ns are unweighted; all data are weighted. Odds ratio of 0.0 means that the odds ratio was less than 0.05 .

proved with a larger sample size. In other words, if our sample had been larger, we could have found a similarly strong association but with tighter confidence bands. The ability to examine relationship variables and several potential covariates is, however, an important advantage of the NSFG over other sources of birth-weight data. We recommend that the relationships among variables that we considered here be examined in future research with larger samples.

The measures of relationship variables we used also have limitations. For example, using the amount of time between first sex with a partner and conception to define the duration of a relationship may not histories. In general, research would benefit from new and better data on women's sexual partners and their relationships, as well as from data on fertility and sexual history collected directly from both women and men. In this regard, we look forward to the next round of the NSFG, which will collect data from samples of women and men and will ask women about the fathers of pregnancies so that the characteristics of fathers will not need to be inferred. With that round of data, we will be able to address the questions we tried to answer here more thoroughly.

Another potential limitation of the NSFG is that the data are retrospective self-reports. Women's recall may be poor, particularly when the events took place more than four years before the interview. In addition, women's recall may be influenced by current feelings; for example, a woman's report of sexual partners and relationship characteristics may be influenced by her feelings toward a current partner. Women may also underreport what they perceive as socially undesirable or negative attitudes or behaviors, such as smoking during pregnancy.

In our research, we were limited to relationship variables that could be created from data collected in the 1995 NSFG. We found that the characteristics of women and of pregnancy and delivery differed significantly by relationship type and duration at conception. Grouping all unmarried women together masks important differences between women who are cohabiting with their partners and those in some other type of nonmarital relationship. Differences in reports of pregnancy intendedness and maternal smoking are particularly striking. In addition, women in relationships in duration of one year or less differ from women in longer relationships. It is important to emphasize, however, that relationship type and relationship duration do not capture the diversity or quality of relationships experienced by men and women. Future research should examine aspects of relationships such as commitment, intimacy and involvement, which may have implications for maternal and child health.

Despite the limitations of our research, the findings reinforce the need to consider relationship characteristics when examining the association of mother's "union status" and birth outcomes. The quality of relationships and the level of social support provided by partners or other individuals may be more important than formal marital status. Although unmarried women in the United States have 
higher rates of low birth weight than married women, ${ }^{16}$ many unmarried women are at no greater risk of low birth weight than their married counterparts.

\section{References}

1. U.S. Department of Health and Human Services (DHHS), Report to Congress on Out-of-Wedlock Childbear ing, Hyattsville, MD: DHHS, 1995; and Ventura SJ et al., Births: final data for 1997, National Vital Statistics Reports, 1999, 47(18):7-8, Table C.

2. MacDorman MF and Atkinson JO, Infant mortality statistics from the 1996 period linked birth/infant death data set, Monthly Vital Statistics Report, 1998, Vol. 46, No. 12, Suppl.; and Ventura SI, Births to unmarried mothers: United States, 1980-92, Vital and Health Statistics, 1995, Vol. 21, No. 53, pp. 21-23.

3. Bennett T, Marital status and infant health outcomes, Social Science \& Medicine, 1992, 35(9):1179-1187; Bennett $\mathrm{T}$ et al., Maternal marital status as a risk factor for infant mortality, Family Planning Perspectives, 1994, 26(6): 252-256 \& 271; Cramer JC, Social factors and infant mortality: identifying high-risk groups and proximate causes, Demography, 1987, 24(3):299-322; Sung JFC et al., Interactive effect of race and marital status in low birthweight, Ethnicity \& Disease, 1993, 3(2):129-136; and Sung JFC et al., Maternal factors, birthweight, and racial differences in infant mortality: a Georgia populationbased study, Journal of the National Medical Association, 1994, 86(6):437-443.

4. Bumpass LL and Sweet JA, National estimates of cohabitation, Demography, 1989, 26(4):615-625, Table 3.

5. Abma J et al., Fertility, family planning, and women's health: new data from the 1995 National Survey of Family Growth, Vital and Health Statistics, 1997, Vol. 23, No. 19, Table 33.

6. Doucet H, Baumgarten M and Infante-Rivard C, Low birth weight and household structure, Journal of Devel opmental and Behavioral Pediatrics, 1989, 10(5):249-252.

7. Manderbacka Ket al., Marital status as a predictor of perinatal outcome in Finland, Journal of Marriage and the Family, 1992, 54(3):508-515.

8. MacDonald LD, Peacock JL and Anderson HR, Marital status: association with social and economic circumstances, psychological state and outcomes of pregnancy, Journal of Public Health Medicine, 1992, 14(1):26-34.

9. Albrecht SL, Miller MK and Clarke LL, Assessing the importance of family structure in understanding birth outcomes, Journal of Marriage and the Family, 1994, 56(4): 987-1003.

10. Thomson E, et al., Male Fertility in Relation to Union Formation and Dissolution, report prepared for Nationa Institute of Child Health and Human Development Workshop Improving Data on Male Fertility and Family
Formation, The Urban Institute, Washington, DC, Jan. 16-17, 1997.

11. Chomitz VR, Cheung LWY and Lieberman E, The role of lifestyle in preventing low birth weight, The Fu ture of Children, 1995, 5(1):121-138.

12. Bennett $T, 1992$, op. cit. (see reference 3); Bennett $T$ et al., 1994, op. cit. (see reference 3); Cramer JC, 1987, op. cit. (see reference 3); Sung JFC et al., 1993, op. cit. (see reference 3); and Sung JFC et al., 1994, op. cit. (see reference 3).

13. Chandra A, Health aspects of pregnancy and childbirth: United States, 1982-88, Vital and Health Statistics, 1995, Vol. 23, No. 18; Ventura SJ et al., Report of final natality statistics, 1995, Monthly Vital Statistics Report, 1997, Vol. 45, No. 11, Suppl. 2, Table 43; and unpublished data from the 1995 National Survey of Family Growth.

14. Ventura SJ et al., 1999, op. cit. (see reference 1), pp. 3-4, Tables 1 and 6, pp. 14-15, Table G; and U.S. Bureau of the Census, Marital status and living arrangements: March 1998 (update), Current Population Reports, 1998, Series P20-514, unpublished tables, detailed tables, Table

15. Doucet $H$, Baumgarten M and Infante-Rivard C, 1989 , op. cit. (see reference 6); Manderbacka K et al., 1992, op. cit. (see reference 7); MacDonald LD, Peacock IL and Anderson HR, 1992, op. cit. (see reference 8); and Albrecht SL, Miller MK and Clarke LL, 1994, op. cit. (see reference 9).

16. Ventura SJ, 1995, op. cit. (see reference 2). 